\title{
Dragline Stripping Method Review to Maximize Productivity and Coal Recovery at Major Fault Zone - A Case Study
}

Shishir Gupta ( $\sim$ shishirgupta111@gmail.com )

Sasan Power Limited https://orcid.org/0000-0002-6973-1317

Rahul Kumar

Sasan Power Limited

Umesh Mahato

Sasan Power Limited

Russell Conley

SMS Mining Services

Keywords:

Posted Date: April 21st, 2021

DOl: https://doi.org/10.21203/rs.3.rs-442916/v1

License: (c) (i) This work is licensed under a Creative Commons Attribution 4.0 International License.

Read Full License 


\section{Abstract}

The authors have requested that this preprint be removed from Research Square. 